\title{
Emotions, policy support and political actions during the Covid-19 pandemic
}

\author{
Emma A. Renström ${ }^{1 *} \&$ Hanna Bäck ${ }^{2}$ \\ ${ }^{1}$ Department of Psychology, University of Gothenburg, Gothenburg, Sweden \\ ${ }^{2}$ Department of Political Science, Lund University, Lund, Sweden \\ * Correspondence: \\ Corresponding Author \\ Emma.Renstrom@psy.gu.se
}

\begin{abstract}
The Covid-19 pandemic has significantly changed the lives of most people. It has been described as the most severe global health disaster of modern times by the United Nations. No doubt such a major crisis influences what citizens think of different policies, and how they become politically active, not to mention, the forceful emotional experiences that the Covid-19 pandemic brings. In this study, we evaluate how emotions affect support for policies related to restricting the spread of the virus and economic assistance, and how emotions affect intentions to engage politically. In an experiment $(\mathrm{N}=$ 1072), we manipulated emotional reactions by highlighting different aspects of the pandemic. Our findings show that the different experimental treatments elicit different emotional reactions, and that fear, anxiety and anger are all related to policy support and political action intentions, but in different ways. Fear and anger predict support for restrictive policies to immediately limit the virus, while anxiety predicts support for economic policies. Anger and anxiety, but not fear, increase intentions to engage politically. Hence, we find support for a mechanism where different aspects of the covid-19 crisis elicit different emotional reactions, which in turn affects policy support and political actions differently.
\end{abstract}

Keywords: Covid-19, Emotions, Policy support, Political action, Parallel mediation 
The Covid-19 pandemic has shaken the world in its foundations and had significant impact on individual and public health (e. g. Arora \& Grey, 2020). If we are to understand how health behaviors and mental health is affected by the pandemic, we also need to understand what kind of polices citizens endorse.

The governmental reactions to the pandemic - how to limit the spread of the virus while at the same time keep a society alive, has differed widely between countries. The most common strategy in the Western European countries has been a complete lockdown with the main goal to stop the virus from spreading uncontrollably, that is, social confinement has in most countries been forced, nationwide and strictly enforced (Bol et al., 2020). Countries such as Austria, France, Norway, Italy, UK, Denmark and the Netherlands had all adopted lockdown policies by the end of March, 2020.

Two major problems with this approach has been noted. First, it is impossible to keep a complete lockdown for an extended period of time - both for economic reasons and for health reasons (Holmes et al., 2020; Huang \& Zhao, 2020; Li et al., 2020). Second, even though lockdowns successfully reduce the spread of the virus, a second wave is feared as restrictions are lifted.

The public's reactions to the different strategies have also varied extensively. In times of crisis, support for the government and its actions often increase (Campbell, 2012), which was also the case in the initial phase of Covid-19 (Bol et al., 2020). However, as time goes on, as the confinement exerts psychological stress on individuals, and both individual and national economy suffer gravely, people are likely to become more negative. Some countries have even faced civil unrest. There is no doubt that this pandemic brings with it a host of emotions, ranging from anger to fear and anxiety. In this article, we explore how emotions affect support for different policies regarding health behaviors to contain the spread of the virus and support for the economy - two types of policies that are often presented as contradictions implying that individuals have to choose between health and economy. We also explore how emotions related to Covid-19 affect citizens' political actions.

\section{Emotions in political psychology}

In clinical and health psychology, there is a long tradition of taking emotions into account. Even though this perspective has been less present in political psychology, there is a now a growing literature that explores how affect influences political actions and attitudes (Brader \& Marcus, 2013; Houghton, 2009; Lambert et al., 2019). Affect is a broad term that includes both emotions and mood. The difference being that mood generally is not associated to a particular stimulus, but emotions are described as "elicited by something, are reactions to something, and are generally about something" (Ekkekakis, 2013, p. 322). In addition, emotions tend to be fairly quick responses that also fade fairly 
quickly. In the present research, we are primarily interested in emotions as reactions to specific stimulus related to the Covid-19 pandemic.

Emotions are important to human life in general, and thus also to political life. Emotions inform individuals about a situation and prepare the body for a certain course of action (Frijda, 1986). Emotions also affect cognitive processing such as attention, information seeking, and reliance on heuristics and stereotypes (Brader \& Marcus, 2013). As such, emotions have an important place in explaining political behavior and attitudes. For instance, it is well-established that emotions are important predictors in collective action and political activism (Goodwin, Jasper, \& Polletta, 2001; Gould, 2009; 2011; Klandermans \& Stekelenburg, 2013), as well as relating to how political information is processed and how political decisions are made (Brader, 2006), and political attitudes in a broader sense (Brader \& Marcus, 2013; Lambert et al., 2019).

There are several different theories on how emotions should be conceived of ranging from a set-up of distinct emotions to a dimensional approach where different emotional states are more fluid. Regardless of how emotions are described, a broad distinction is made by valence, that is the positive or negative nature of emotions. In the past, negative emotions have often been lumped together, regardless of their specific nature, including anger, fear, anxiety, sadness and so on (see e. g. Brader \& Marcus, 2013 for an overview). The widely influential PANAS is an example of this. PANAS stands for Positive Affect (PA) and Negative Affect (NA), and suggest that affect should be conceptualized in terms of these two dimensions (Watson, Clark \& Tellegen, 1988). However, much research suggests that different negative emotions have extensively disparate impact on cognition and behavior. In contemporary political psychology research, one of the most common distinction is that between fear/anxiety and anger. There is much evidence that fear and anxiety, compared to anger, differentially impact cognition and behavior (Bodenhausen et al., 1994; Banks \& Valentino, 2012; Merolla \& Zechmeister, 2013; Marcus et al., 2000).

\section{Anger}

Anger is one of the most well-researched emotions in psychology in general, including clinical psychology. Hence, there is much work on its causes and consequences both on cognition and behavior. Anger has been described as a goal-pursuing and approach-linked emotion, motivating action and decreasing cognitive processing. Anger is related to physical activity and increased blood flow ("fight" response), which also indicates angry individuals engage in less cognitive processing. Several studies have shown that anger leads to confrontation and approach (Carver \& Harmon-Jones, 2009; HarmonJones, Harmon-Jones, Abramson, \& Peterson, 2009; Harmon-Jones, Price, Gable, \& Peterson, 2014) 
The fact that anger has been in the empirical spotlight for such a long time makes anger a good candidate to apply to a political context, and not surprisingly, anger is one of the most explored emotions in political psychology. Anger has been shown to be a strong motivation for people participating in collective actions, such as demonstrations (Klandermans \& van Stekelenburg, 2013). As such, anger has a mobilizing function, which was for example shown by Valentino and colleagues (2011) in their influential paper on the mobilizing effect of anger on voting behavior. One reason why anger has this mobilizing function is that it is elicited by perceived unfairness. Anger is the signal that something must be done to make things just (Lambert et al., 2019). Hence, angry people engage. Anger has also been related to political attitudes and policy support, even though the literature here is not as extensive. For instance, anger, but not fear or anxiety, has been related to support for "hawkish", highrisk governmental policies (Lerner et al., 2003; Sadler, Lineberger, Correll, \& Park, 2005; Skitka, Bauman, Aramovich, \& Morgan, 2006).

\section{Fear and anxiety}

Less attention has been paid to the distinction between fear and anxiety even though there are some indications that these two emotions could have distinctive effects as well (Sylvers et al., 2011). We here draw on Brader and Marcus (2013), who suggest that a possible distinction between fear and anxiety could be important for future research in the field of political psychology. In the present study, we explore these two emotions as separate, and argue that fear and anxiety should have distinctive effects on political attitudes and behavior.

The labels fear and anxiety are often used interchangeably in the political psychology literature (Brader \& Marcus, 2013; Wagner \& Morisi, 2019). It is true that fear and anxiety share many more features as compared to for instance anger, even though all three are considered negative emotions (Watson et al., 1988). Both fear and anxiety are elicited by threats and serve the evolutionary purpose of survival (Lang, Davis \& Öhman, 2000). Even though fear and anxiety in the social and political psychology literature most often are treated as reflecting the same underlying emotion, but perhaps of varying intensity, clinical researchers distinguish between anxiety (such as Generalized Anxiety Disorder) and fear (present in specific phobias) (Öhman \& Mineka, 2001). In DSM-5 (The diagnostic and statistical manual of mental disorders, APA, 2013), anxiety is described as a worry about future events, whereas fear is a reaction to current events. Moreover, fear and anxiety seem to operate through different neural pathways and have different defining characteristics (Sylvers Lilienfeld \& LaPrairie, 2011). 
Fear is a fast emotion in that it is elicited when a threat is imminent or clear and the response also quickly fades. Fear is elicited when a threat is perceived to target the self (Davis \& Stephan, 2006). Fear is associated with a sense of danger, and motivates fleeing behavior, which also suggests that fear is a high-arousal emotion, just like anger. Anxiety, however, is elicited when the threat is ambiguous, uncertain, or less specified, and the reaction is a prolonged emotional state. Since the threat is not defined, anxiety does not motivate fleeing in the same manner as fear and has been shown to lead to a mix of approach and avoidance reactions (Gray \& McNaughton, 2000; Perkins, Inchley-Mort, Pickering, Corr, \& Burgess, 2012). Previous research on fear has shown that fear increases risk estimates and precautionary planning (Lerner et al., 2003). Fear also evokes uncertainty and feelings of lack of individual control, which are central in determining risks (Lerner \& Keltner, 2001; Slovic, 1987).

There is an extensive body of research in political psychology about how threat affects political attitudes and political behavior. Although, it should be noted that emotions are usually not measured in this line of research (Lambert et al., 2019), which means that even if threat has been found to influence attitudes and behavior, the specific nature of why threat has certain effects is not empirically investigated. Much of the previous research that has examined the relationship between threat and political attitudes or behavior have focused on intergroup threat (such as terrorist threat, or the threat of immigration). The observed following attitude shift has also mainly been related to political attitudes relating to the threat, such as more restrictive immigration policies, increased military spending following the 9/11 terrorist attacks, but not on other issues related to ideology such as feminism or socialized medicine (Nail \& McGregor, 2009). Research that use other types of threats, such as existential threat in the mortality salience literature, have found mixed effects on political attitudes (Burke, Martens \& Faucher, 2010). A possible explanation to such mixed results is the lack of emotion measures that could function as mediators.

Research from the terror management literature has shown that the existential threat elicited by the thought of an unavoidable and imminent death do elicit existential anxiety (Greenberg et al., 1990; Pyszczynski et al., 2003). Mortality salience has been linked to political conservatism, increased nationalism and increased Republican voting. This effect has been labelled the 'conservative shift' hypothesis (Jost et al., 2003; Arndt et al., 2002; Landau et al., 2004), and is based on research which has linked existential anxiety with a low tolerance for ambiguity. Relatedly, a recent study found that existential anxiety was related to voting for the more secure, status quo, option in the Brexit referenda (Bäck et al., 2020). Another study found that experimentally induced financial anxiety increased 
political participation when participation was easy and immediate, such as signing an online petition (Denny, 2016).

The research mentioned above use mainly experimentally induced anxiety, but there are also individual variations in trait anxiety. One study investigated the relation between trait anxiety and political attitudes and found weak relations that anxiety disorders were related to concerns about economic inequality and environmental issues (Helminen, 2018). These specific concerns seem fitting, given that anxiety is related to an ambiguous (future) threat. In relation to anxiety disorders, anxiety could potentially be a source of action. Obsessive-compulsive disorder, which is specified as an anxiety disorder by ICD-10 (WHO), is clearly action-oriented. People with this disorder tend to have specific behavioral rituals that aim to relief feelings of discomfort (Soomro, 2012).

The above literature review indicates that anxiety have effects on attitudes, such that it increases a preference for what is known and safe, but also on political behavior such as voting for the safe option (Bäck et al., 2020), or other more low-cost political actions (Denny, 2016). So, it seems that anxiety may have some effects both on political attitudes and political behavior, but more research on this link is clearly needed. All in all, there is very little research on how fear, and especially in contrast to anxiety, affect political attitudes and political behavior. One reason for this is that the development of good measures for discrete emotions to be used in self-report surveys has fallen behind (Harmon-Jones, Bastian \& Harmon-Jones, 2016).

The present study utilizes the situation with the Covid-19 pandemic to explore how different negative emotions, specifically anger, fear and anxiety, influence policy attitudes and political action intentions. Before specifying our hypotheses, we briefly describe the Covid-19 context and focus particularly on Sweden where the present research was conducted.

\section{Expectations about emotions and policies in relation to the Covid-19 pandemic}

\section{Policies in relation to Covid-19 and the case of Sweden}

The Covid-19 pandemic is the greatest challenge of modern times. It is the defining global health crisis since World War Two (UN, 2020), and poses a serious threat to many democracies. As such, it is of utmost importance to understand how individuals function in times of extraordinary distress. How does it affect their political attitudes and behavior? How should governments act in such a serious crisis?

In an overview of policies implemented in reaction to Covid-19, Cheng et al., (2020) present data of over 10000 policy announcements in over 190 countries. They find that the most commonly 
implemented policy is to close national borders. The second most common policy is to close schools and non-essential businesses. In most cases, the implementations were also compulsory. Such measures undoubtedly affect citizens both individually and as a nation. A growing literature focuses on the negative health aspects of confinement (e. g. Arora \& Grey, 2020).

The Swedish approach has differed compared to most other countries in that Sweden did not go for a lockdown strategy. Even though often claimed in international media, the goal has not (at least not officially) been to reach herd immunity per se, but that should rather be seen as a consequence of the more lenient Swedish approach. The goal has been to "flatten the curve", that is, to allow the health care system to keep up and avoid a collapse. Essentially, this means that the goal of the Swedish approach does not differ from the goals of most other countries' governments.

But the means to reach the goal has differed. Whereas most other countries opted for restrictions that are regulated by law enforcement, the Public Health Agency of Sweden provided recommendations for individual behavior. The term recommendation is heavily culturally dependent and also varies with sender within Sweden. As Prime minister Stefan Löfven stated in a rare speech to the public on March, 22, when the Public Health Agency gives a recommendation, it is expected that the public complies - it is not a choice to do it or not, you should do it. Still, there is no punishment for citizens if they do not follow the recommendations. The recommendations were among others to keep distance, avoid non-essential travels, increased hand hygiene, and to stay at home and work from home as much as possible. Even though there are legal enforcement of restrictions for bars and restaurants for example, individuals' freedom is still largely unregulated. Shops and businesses remained open during the crisis during the entire spring, as did pre-schools and basic schools.

One argument for this approach, presented by the Public Health Agency, is that it should be possible to keep up for a prolonged period of time, in contrast to complete lockdowns. Even though many businesses struggle, most people can still work, either from home or at their work place. Children can keep up relatively normal lives, and the general psychological distress should at least be lower as compared to what it is likely to be in many other countries. This relatively lenient strategy makes Sweden an excellent case for exploring health behaviors.

The specific case of Sweden has both shocked and amazed across the world. Some have watched in disbelief, but as the data comes in, it seems that the recommendations have clearly affected the Swedes' behavior. For instance, the curve has flattened (see www.folkhalsomyndigheten.se, for the latest statistics). Data from cell phone companies show that travels during the Easter break was severely reduced (e.g. SVT, 2020). Nonetheless, the debate about the "correct" approach is still ongoing and stirring emotions both within Sweden and internationally. Early summer 2020 (June) Sweden had much 
higher Covid-19 mortality rates compared to, for instance, the other Nordic neighbor countries which employed lockdown strategies.

Another important part of the Swedish system in general is that it is a strong welfare state. For instance, all higher education is subsidized by the government, as is pre-school child care and the parental leave policy is among the most generous in the world. The social security system ensures health care for all citizens and enables paid sick leave.

In relation to Covid-19, the government quickly launched several economic support packages to handle the economic consequences of the "flatten the curve" directions issued by the Public Health Agency. Examples of these that have individual-level consequences are for instance that employees could stay at home for up to two weeks without a medical certificate and still be eligible to paid sick leave (normally, a medical certificate is needed after 8 days). Also, the first day at home, which is normally not covered by the sick leave pay, was abolished (see Forsakringskassan.se for more information about these policies). For companies, the government also launched major economic support packages. For instance, companies that had to lay off staff, were compensated such that if they kept their staff and paid them a certain percentage of their wages, and the state covered the rest of the wage. This made sure that companies could still keep their staff and that employees still had incomes (see government.se for more information about policies).

The Covid-19 pandemic brings with it two main problems that any government had to deal with. First, there is the problem of restricting the spread of the virus, but a secondary problem to the policies implemented to reach the first goal, is the sudden and severe strain on the economy, both individually and nationally. Hence, the solutions or measures to deal with these problems are to some extent contradictory - stay at home policies are by nature harming the economy, while no such policies would overwhelm the health care system and lead to increased fatalities. The question of interest here is when and why do people support different kinds of policies? We here expect that support for the different kinds of policies should be dependent on the individual's emotional state.

The present research aims to explore how emotions, elicited by a specific stimulus, affect both political attitudes in the form of policy support and political action intentions. The emotions that we are interested in is anger, but also fear and anxiety as separate emotions. In the following sections, we elaborate on the hypotheses that we evaluate in this study.

\section{Hypotheses about emotions and policy support}

In relation to the Covid-19 pandemic, different policies have been discussed. Most prominent and urgent has been the policies that aim to restrict the spread of the virus - to "flatten the curve". To handle 
this situation, most of the Western European countries employed strict lockdown policies. But this of course brought along other problems, mainly economical, but also psychological (Matias et al., 2020) and physiological (Arora \& Grey, 2020). When it comes to policies to support the economy, the variation between countries have been far wider as compared to the "flatten the curve"-policies. We formulate hypotheses about how we expect emotions to influence attitudes towards the two kinds of policies in Sweden.

First, we expect that anger is mainly related to support for policies directed at limiting the spread of the virus. This should be the case since people in this condition should feel angry with others that disobey the Public Health Agency's recommendations, which should increase support for policies that restrict individual freedom. This could be seen as a way to "get back" at the transgressors. Second, previous research show that anger is related to more aggressive policies (Sadler et al., 2005; Skitka et al., 2006), and the policies directed to limiting spread severely limits individual freedom. Hence, we expect that: focusing on transgressors of the Public Health Agency's recommendations should lead to anger, which in turn is likely to increase support for restrictive policies (H1a). We do not expect that anger will affect support for economic policies.

Second, fear should be related to concerns for the own health foremost and hence we expect that fear should be related to support for policies targeting spread control ("flatten the curve"). We thus hypothesize that: focusing on the virus and the strained health care situation should lead to fear, which in turn is likely to increase support for restrictive policies (H1b). We do not expect that fear will affect support for economic policies.

Third, given that anxiety should be related to a prolonged concern, compared to fear, we expect that anxiety will have a stronger impact on support for policies related to the economy. The economic threat of the Covid-19 pandemic is less clear and it is uncertain how life will pan out in the post-crisis period. Here, we also draw on Fetzer et al., (2020), who found that focusing on the mortality rate of Covid-19 increased economic concerns in a US population. Hence, we expect that: focusing on the virus and strained health care situation should lead to anxiety, which in turn is likely to increase support for economic policies (H1c).

\section{Hypotheses about emotions and political actions}

Anger is an action-oriented emotion and has long been considered a predictor of political activity, hence we here expect that anger will increase intentions to engage in political actions. We thus hypothesize that: focusing on transgressors of the Public Health Agency's recommendations should lead to anger, which in turn is likely to increase political action intentions (H2a). 
Regarding fear, we expect that fear is not linked to political engagement or possibly even negatively related to engagement, since fear is generally related to avoidance. Hence, we do not specify a hypothesis for fear and political action intentions.

Since there is very little prior research on anxiety and political engagement, it is not straightforward to hypothesize about its effects. Nonetheless, since anxiety is related to an ambiguous threat and a prolonged emotional state, we believe that anxiety could also be related to increased political action tendencies. However, we make this claim with the precondition that the political activities that we measure here are of a fairly specific nature. Since participating in demonstrations is not an option in relation to the Covid-19 pandemic, the actions are more in the form of online participation. This would be in line with the study by Denny (2016), who found that financial anxiety was related to political participation when participation was measured as signing an online petition. We expect that: focusing on the virus and strained health care situation should lead to anxiety, which in turn is likely to increase political action intentions ( $\mathrm{H} 2 \mathrm{~b})$.

\section{Overview of the study}

The present study is an experimental study where we employ two experimental treatments designed to elicit different emotional responses - either anger, or fear and anxiety. The two experimental conditions consisted of short fictive news articles (about 300 words each).

The first one focused on the virus, the limits of the health care system when dealing with too many intensive care patients, the dangers of the virus and estimates of deaths and severe cases. To make it more relevant to the individual, we highlighted potential consequences of worst case scenarios such that it would entail that almost everybody would be severely affected by the disease - either themselves or someone close to them. We also highlighted that the need for intensive care is not restricted to the elderly population. The aim with this text was to present both a concrete and specific stimulus that would elicit fear, where specific measures could help to avoid it, and a more ambiguous stimulus that could elicit anxiety. Even though the virus is a specific source of fear, its future consequences are not clear and hence could function to elicit anxiety. In a pre-print, Fetzer and colleagues (2020) find that economic anxiety increased following the entrance of Covid-19 in the US as measured by a substantial increase in google searches for economic recession, as well as survey data. Further, they also found that focusing on the high mortality rate of Covid-19 led to increased economic worries.

The second condition described people who defied authority recommendations to stay at home, and because of this, contributed to unnecessary spread of the virus. The data was collected just before Easter, when the whole basic school system has a one week break and this break is often spent going 
skiing or on holidays abroad. On the 15th of March, just three weeks before the Easter break, the Ministry for Foreign Affairs issued a recommendation to avoid all non-essential international travels. This led to a fear that people would instead travel within Sweden and hence spread the virus. Especially, focus was on the Stockholm region which was the epicenter of the disease in Sweden, while most other parts of Sweden remained fairly unaffected. Health care workers from around Sweden expressed their concerns that travelers would bring the virus there, and with limited capacity of health care institutions in smaller regions, they were dreading a disaster. Hence, the text focused on that the possibility some people might disregard the recommendations to stay at home and go travelling to the Swedish skiing resorts, the south of Sweden or the archipelagos regardless of the recommendations. This ensured that we had a clear focus on specific transgressors where the idea was that their behavior would be perceived as unjust and egoistic and elicit anger. Research shows that when violations of justice are severe and transgressors are clearly identified, anger is the prime emotion (Aquino, Tripp, \& Bies, 2001; Bennett \& Earwaker, 1994; Bradfield \& Aquino, 1999; Darby \& Schlenker, 1982; Lickel, Miller, Stenstrom, Denson, \& Schmader, 2006).

Importantly, everything in the texts were taken from real life news and debates so the texts did not present anything untrue or something that the participants would not encounter just reading a newspaper or watching the news on television. We simply summarized different aspects of the pandemic and presented to the participants. Translations of the texts are found in the supplementary material.

\section{Method}

\section{Procedure and Measures}

The present research was conducted in Sweden using an online survey experiment. We first pretested the material to make sure the conditions did in fact elicit the expected emotions. The pre-test led to minor changes and also some changes in the emotion scale that we used so that we would be better equipped to capture the emotions of interest. The changes that we made to the stimulus material were small and mainly done to increase emotional reactions. For instance, we made it even more explicit that the virus was very dangerous and that most people would probably somehow be affected by it. Data was collected by the survey company Enkätfabriken. Participants $(N=1072)$ were randomly assigned one of the two conditions. Data was collected between 2nd to 7th of April, 2020. 
Participants were first informed about the study and its purpose, how data was to be treated and their right to withdraw at any time. Before starting the survey, the participant was required to provide informed consent.

First, participants responded to some demographic variables such as age, gender, education, selfpositioning on a left-right scale $(1=$ Clearly to the left, $10=$ Clearly to the right $)$, and a liberalconservative scale $(1=$ Clearly liberal, $10=$ Clearly conservative $)$, and political interest $(1=$ Not at all interested, $10=$ Very interested). These were used as control variables in our analyses.

The participants then read one of the short news pieces that constituted our main independent variable, and was designed to elicit either anger or fear and anxiety. Following the news piece, we assessed the participant's emotional state. The measure that we used is based on Harmon-Jones and colleagues' Discrete Emotions Questionnaire (2016). We first pre-tested the translation of the entire Discrete Emotions Questionnaire in relation to our stimulus material. This pre-test showed that some items did not translate very well, so we made some changes. First, the item "Grossed out" was extremely skewed (2.14). Since the disgust scale was not our main interest, we removed this item. Second, when running reliability analyses on the Sadness subscale, the item "Lonely" decreased Cronbach's alpha. Again, sadness was not our main interest and hence we dropped Lonely in the main study.

We also removed some items from the emotions that were of less interest to the present study, to shorten the questionnaire. For instance, we removed the happiness subscale entirely, since it made little sense to rate happiness in relation to Covid-19. We also removed the relaxation and desire subscales. Finally, we added some items to even better capture the emotions we were primarily interested in: anger, fear and anxiety. The question read: The situation with Covid-19 can give rise to a range of different emotions. In relation to Covid-19, what emotions do you experience? Then participants rated on scales from $1=$ Do not experience at all to 7 = Strongly experience, different emotions. We were mainly interested in the three emotions anger, anxiety and fear but included some other emotion items that potentially could affect the results as well.

Anger was measured with the items rage, anger, irritation and upsettedness. Fear was measured with the items fear, scare, terror and alarm. Anxiety was measured with the items anxiety, nervousness, unpleasantness, worry, helplessness, apprehension and powerlessness. Two items related to anger and fear were removed due to being highly skewed (fury:1.46, and panic: 1.42). None of the other focal emotion items had a skewness statistic $>1$, nor outliers $>3$ standard deviations (see the Supplementary material for individual skewness statistics). The items were collapsed into three indices and Cronbach's alpha was high in all of them: anger $=0.87$, fear $=0.88$, and anxiety $=0.90$. The other items we included 
measured sadness: sorrow, sadness, and emptiness (alpha $=.74)$, disgust: disgust and sickness $(r=.46$, $p<.001)$, and finally, empathy: empathy and compassion $(r=.70, p<.001)$.

After the emotion measure, we asked a set of policy opinion questions relating to the economy and limiting the spread ("flatten the curve") (the order of the two sets of policy items was randomized), and intentions to engage in political actions.

The question regarding policy opinions about the economy read: Sometimes the need to restrain the spread of the virus is contrasted to the risk that the economy is affected. The government has already taken some measures to facilitate for some industries and individuals that are severely affected by the corona crisis. The policy suggestions below have been discussed as additional measures. What is your opinion about them? The scale ranged from $1=$ Very bad suggestion to $7=$ Very good suggestion. The items were: Economic support to affected companies, Increase sick leave without written medical certificate to one month (a previous measure was to allow sick leave for two weeks without medical certificate, which is normally one week to be eligible for sick leave compensation), Pay employers' part of the sick leave costs, Extra benefits for housing to individuals that have lost their jobs, Abolished demands for housing payments for three months (this measure was actually later implemented until 2022), Lowered sales taxes to stimulate consumption. The items were combined to a mean index, Cronbach's alpha was .77.

The question regarding policy opinions about limiting the spread of the virus read: Below are some suggestions of measures that have been taken in other countries and that are discussed in Sweden to limit the spread of contamination. How good do you think these suggestions are? Answers were again made on 7-point scales from $1=$ Very bad suggestion to $7=$ Very good suggestion. The items were: Close pre-schools and basic schools (the equivalent to high schools and higher education institutions were already switched to distance teaching), Limit the number of people that are allowed to meet to two, Use police and military to ensure citizens follow the restrictions, Forbid non-necessary travelling within Sweden, Close all restaurants and cafés, Only allow online shopping of groceries, Stop gatherings of more than 10 people, Close the borders for both in- and out-bound travels, Total lockdown that is, people are not allowed to leave the home more than one person at the time for essential errands. The items were combined to a mean index and Cronbach's alpha was .87 .

Intentions to engage in political actions was measured with the question: Sometimes people want to affect politics by engaging. In relation to the outbreak of Covid-19, is there any of the following activities that you could consider doing? The answers were made on a 7-point scale from $1=\mathrm{No}$, cannot consider doing, to $7=$ Yes, can absolutely consider doing. The items were: Share information on social media (such as news articles), Post or comment on social media, Sign an online petition, 
Contact politicians or authorities, Discuss the government and public health agency's measures with friends. The items were combined to a mean index, and alpha was .78.

\section{Participants}

Out of the 1072 participants, 547 (51\%) were in the fear/anxiety condition and $525(49 \%)$ in the anger condition. There were 496 men and 505 women in total ( 71 did not answer the gender question). In the fear/anxiety condition there were 244 men and 271 women, and in the anger condition there were 252 men and 234 women. Mean age was 50 years old, $S D=15.57$, range 18-88. Age did not differ between conditions, $t(984)=0.30, p=.76$. The sample was fairly highly educated: 1 person had not completed basic schooling, 68 had only basic schooling, 336 had the equivalent of high school, 112 had post high-school vocational training, 482 had higher education (college or university), 13 had post-graduate education, and 60 participants did not answer the education question. The distribution of education between the conditions were as following where the fear/anxiety condition is presented first, then the anger condition: No basic schooling: 0/1, Basic schooling: 37/31, high school: 169/167, post high-school vocational training: 57/55, higher education: 248/234, post-graduate education: 10/3.

The participants were fairly centrist when it comes to left-right position, $M=5.41, S D=2.32$, and liberal-conservative, $M=4.74, S D=2.00$. They were also fairly interested in politics, $M=5.68, S D=$ 2.54 on the 10-point interest in politics scale. To make sure that there was no difference in the control variables across the experimental conditions, we t-tested the ideological positioning scales (left-right, liberal-conservative) and interest in politics between the conditions. There were no significant differences, $t \mathrm{~s}<1.34, p \mathrm{~s}>.18$.

\section{Empirical results}

We first present some descriptive results. Table 1 shows means and standard deviations on the mediation variables split on condition along with results from separate t-tests.

\section{[Table 1 about here]}

There were significant differences on all three of the focal emotion indices. As expected, fear was higher in the fear/anxiety condition focusing on contamination and spread of the virus compared to the anger condition, and anger was higher in the anger condition compared to the fear/anxiety condition. Anxiety was also higher in the fear/anxiety condition compared to the anger condition. This shows that the information in the stimulus texts successfully affected the participants' emotional state. Even 
though we did not have any expectations about sadness, sadness was significantly higher in the fear/anxiety condition compared to the anger condition. Disgust and empathy did not vary with condition. Hence, we include sadness, but not disgust or empathy, in our main analyses (see the Supplementary material for analyses including all emotion indices).

Table 2 shows means and standard deviations for the dependent variables, split on condition. There were no significant differences between the conditions on any of the outcome variables, $t$ s absolute values $<1.5, p \mathrm{~s}>.12$. In the following analyses, all $p$-values below .05 will be considered significant.

[Table 2 about here]

Table 3 shows correlations between the emotions and the outcome variables. As can be seen, there were fairly strong correlations between most emotions and opinions and action intentions. All emotions were positively related to policy support for both economic and spread control policies. All emotions were also positively related to political action intentions.

\section{[Table 3 about here]}

To test our hypotheses that highlighting different aspects of the Covid-19 outbreak will lead to different emotional reactions, which in turn affect policy support, and political action intentions, we performed a series of parallel mediation models, one for each dependent variable. In all models, we controlled for age, gender, education, ideological position (both left-right and liberal-conservative), and political interest. We also included sadness in all models since sadness was experimentally elevated in the fear/anxiety condition. Finally, in the Supplementary material we include models with all emotions. We used Hayes' PROCESS macro, model 4. The results can be seen in Table 4, which shows the regression results, and Table 5, which shows the bootstrapping results, and the effects are illustrated in Figure 1, where panel A and B show the effects on policy support, while panel $\mathrm{C}$ show the effect on Political Actions.

[Table 4 about here]

[Figure 1 about here] 
As can be seen there is an effect of condition on all three focal emotions. Anger is higher in the anger condition, and fear and anxiety are higher in the fear/anxiety condition. In these models, the effect of condition on sadness did not quite reach conventional significance levels $(p=.052)$.

Gender had a significant effect on all emotions such that women reported stronger emotional experiences overall. There was a weak negative effect of age on anger and anxiety indicating that both anger and anxiety tended to decrease with higher age. Higher education was related to less anger but not to any other emotion. Ideological position on a left-right scale had no effect on emotions. However, people who were more conservative, reported stronger emotional experiences overall, except for sadness. Higher political interest was weakly related to anxiety.

In the first hypothesis (H1a) we hypothesized that when information focused on people who disobeyed the Public Health Agency's recommendation, people would experience anger and, in turn, anger would predict support for more restrictive policies. As can be seen in Table 4, the coefficient for anger on support for restrictive policies was significant, in support of H1a. The results indicate a full mediation of anger since there was no direct effect of condition on the outcome variable when the mediator was included in the model, as seen in Table 5.

[Table 5 about here]

Hypothesis $\mathrm{H} 2 \mathrm{~b}$ stated that when information focused on the virus and the strained health care situation, this would elicit fear, which in turn would also predict support for restrictive policies. Again, the coefficient between fear and restrictive policy support was significant, indicating support for $\mathrm{H} 2 \mathrm{~b}$ and full mediation, as seen in Table 5.

Hence, both anger and fear were related to increased support for more restrictive policies, so called "flatten the curve"-policies. Age, gender and left-right position was unrelated to support for restrictive policies, while higher education and higher political interest was related to lower support, more conservative self-positioning was related to more support.

Hypothesis H1c stated that information focusing on the virus and health care situation should also elicit anxiety, and this in turn should be related to support for economic policies since anxiety is rather related to an ambiguous stimulus. As can be seen the coefficient for anxiety on economy policy support was significant, such that higher anxiety was related to more support for economy policies. There was a complete mediation, where information focusing on the spread of the virus and the strain on the health care system led to increased anxiety which in turn was responsible for support for economic policies. These results clearly support hypothesis H1c. 
There were no effects of the other emotions on economy policy support. Again, education was negatively related to policy support such that higher education was related to lower support for economy policies. None of the other control variables exerted a significant effect.

Finally, we expected differential effects of emotions on political action intentions. H2a stated that information focused on transgressors would lead to anger, and anger would increase political action intentions. As can be seen in the last column of Table 4, there was a positive effect of anger on political action intentions indicating that angry people were more likely to be willing to engage politically. $\mathrm{H} 2 \mathrm{~b}$ stated that information about the virus leading to anxiety should also increase participation intentions. In line with this, we find that the coefficient for anxiety on political action intentions was positive, indicating that anxious people were more willing to engage politically. Neither fear nor sadness was significantly related to political action intentions.

Interestingly, there were weak or no effects of ideological position on the outcome variables. Leftright position had no effect on either policy, nor political action intentions. Liberal-conservative position had a positive effect on restrictive policies such that individuals who rated themselves as more conservative were more in favor of restrictive policies. This result is in line with research on conservatism and authoritarianism and restrictive policies in general (McKeever, 2020; Poteat \& Mereish, 2012). There was also a weak negative effect of conservatism on political actions, which is also in line with previous research on political engagement and ideology.

However, these results also indicate that the policies related to the handling of the Covid-19 pandemic do not follow partisan lines. Not even the traditionally economic left-right scale had any influence on the economic policies, which largely follow from ideological differences. In relation, in a pre-print based on an experiment testing partisan endorsement of Covid-19 in the US, Gadarian et al. (2020) did not find any partisan effects on health behaviors or policy attitudes.

Finally, there was a weak negative effect of political interest on restrictive policy support such that those who were more interested in politics were less supportive of restrictive policies, and a positive effect of political interest on political action intentions such that increased political interest was also related to increased intentions to engage. This latter result is in line with results found in previous research on political interest and engagement, both offline and online (Gibson \& Cantijoch, 2013; Oser, Hooghe \& Marien, 2013).

We also ran three separate regression analyses, one for each dependent variable, using the three focal emotion indices and sadness as predictors, as well as the control variables. These analyses mirrored the results found in the parallel mediation models. 


\section{Discussion}

The present research has analyzed the emotional reactions to different aspects of the Covid-19 pandemic, and has explored how different emotions relate to attitudes towards different policy proposals and to political action intentions. The experiment performed as part of this study, consisting of two conditions, highlighted either transgressors of the Public Health Agency's behavioral recommendations and was designed to elicit anger, or the danger of the virus, the strained health care situation, and uncertainty of deaths and severely ill citizens, designed to elicit fear and anxiety.

Using an adapted variation of Harmon-Jones et al's (2016) measurement of discrete emotions we found that the information provided to participants elicited the expected emotional reactions. Subsequent modelling showed that both fear and anger led to support for more restrictive policies, but for arguably different reasons. In the anger condition, the information was focused on justice violations by specific individuals which led people to become angry. Restrictive policies for these people should be related to restriction of transgressors' possibility to violate recommendations - to restore justice and fairness.

For fearful individuals, however, restrictive policies should be related to a desire to limit the spread of the disease. Participants who reported higher levels of fear were informed about the danger of the virus and the situation with a possible overwhelmed health care system. For these individuals, restriction should mainly be enforced to restore a sense of control and security. Relatedly, a recent paper (Harper et al., 2020) showed that fear was related to increased public health behaviors such as social distancing and increased hand hygiene.

Even though fear and anger are fundamentally different emotions, they are both high-arousal emotions (Marcus et al., 2000). This could explain why they both are related to restrictive policies focusing on the situation here and now, but not economic policies. To support economic policies, individuals need to extend their focus beyond the immediate situation and evaluate what might come after the pandemic has passed. Such an extended focus may be difficult under states of high-arousal, which tends to narrow the attentional span (Brader \& Marcus, 2013). Anxiety however is related to increased attention to information and less reliance on prior convictions (Brader \& Marcus, 2013). This was also found by Banks and Valentino (2012), who showed that while anger strengthens reliance on prior convictions regarding racist attitudes, anxiety in fact had the opposite effect, undermining such use of heuristics.

In line with much previous research on emotions and political activity (see e.g. Brader \& Marcus, 2013), we found that anger increased intentions to engage in political actions. In a study by Brader et 
al (2010), it was found that when faced with a potentially deadly viral outbreak, angry citizens were more likely to engage politically by for instance contacting officials, and demanding investigations and prosecution of those responsible for the outbreak. Fearful individuals, however, were more likely to engage in protective behaviors such as wearing a face mask, increasing hand hygiene and reading up on the disease. Because our measure of political actions did not include protective measures, we found effects in line with this study that angry individuals were more likely to engage in political actions.

Interestingly, we also found a full mediation effect of anxiety on intentions to engage politically. The political psychology research to date has not focused particularly on anxiety (Brader \& Marcus, 2013), although some exceptions exist. For instance, Denny (2016) found that financial anxiety led to increased participation in the form of signing an online petition. In our study, we had similar items, that is mainly actions that could be performed online, such as sharing material and commenting online, but also signing petitions and even contact authorities. Another reason to assume that anxiety may increase participation tendencies is that anxious people may tend to see beyond the immediate situation, and previous research show that anxiety heightens attention to information. Even though previous research also show that fear is related to precautionary planning (see e. g. Brader \& Marcus, 2013; Lerner et al., 2003), it may be confounded with anxiety since these emotions rarely have been separated in previous research.

Compared to fear, which is focused on seeking out immediate security from the present situation, anxiety should relate more to future prospects. For instance, in the APA diagnostic manual, DSM-5, anxiety is described as a concern about future events. This idea is further corroborated in our study, where anxiety is related to economic policy support rather than restrictive policy support. Together, this indicates that anxious people have a different focus than fearful people, or angry for that matter.

Relating these results to trait anxiety, or anxiety disorders, they make intuitive sense. Highly anxious people tend to ruminate over certain aspects and hence seek out information and plan ahead. Such behavior should be facilitated in a state of anxiousness compared to fear, where the response is to seek out immediate protection from the fear-arousing stimulus. When it comes to political action intentions increasing among anxious people this could also be related to that anxiety in general can be alleviated by certain actions. For instance, clinical anxiety syndromes, such as obsessive-compulsive disorder, often manifest as rituals, where the goal of certain actions is to decrease anxiety (such as excessive hand washing). An important finding is that generalized anxiety disorder symptoms have increased and are particularly pronounced among individuals ruminating over the Covid-19 (Huang \& Zhao, 2020). 
An important result of the present research is that we did not find any main effects of condition on the outcome variables. This is important because much previous research in political psychology have not assessed emotions as mediators, which could explain previous conflicting results, or null results. In a recent pre-print, for example, Gadarian et al. (2020), did not find any effects of highlighting different aspects of Covid-19 on policy suggestions in a US setting. Lambert and colleagues (2019) refer to "oppositional mediation" (Kenny, 2017), when discussing that a specific stimulus may elicit different positively correlated emotions, such as anger and sadness, which in turn may have opposite effects on a specific outcome variable, such as a certain policy. This would lead to null effects if emotions are not considered in the model.

This study fills an important gap in the literature on emotions and political attitudes and behavior, and shows that the same imminent threat (Covid-19) could lead to widely different emotional reactions among individuals depending on framing, which in turn lead to different, or even the same outcomes, but for different reasons. This study also highlights the importance of emotions in political life, and that researchers in political psychology should increasingly pay attention to individuals' emotional states. In addition, we argue that it is fruitful to separate between different negative emotions, even beyond splitting up anger and other negative emotions. We have here focused specifically on anger, fear and anxiety, but depending on the topic and research question, other emotions may also be relevant, such as pride or enthusiasm (Brader \& Marcus, 2013; Lambert et al., 2019). We see here that these emotions, even though they are elicited by the same information, lead to very different outcomes both support for different policies and political action intentions. This means that much previous research in the field of political psychology that has used threat to manipulate attitudes and behavior may be confounded with differential effects of emotions that have not been measured.

Some limitations of the present study should be mentioned. Even though we did our best to produce stimulus material that would function to elicit specific emotions, the stimulus material was consistent within each condition. That is, the results would have been stronger and more generalizable should there have been different versions of the texts that elicited fear/anxiety and anger respectively. Hence, an important next step is to include different stimulus materials within each condition. Another, related issue, is that the texts differed in content. This means that we cannot be completely certain that there are no other factors that may be responsible for the results, besides the emotional reactions. Because the topic of the two texts were both highly discussed and presented in the media at the time, we cannot know if participants used only the information provided in the texts to form their policy attitudes, or if they also relied on prior knowledge. This too, is an empirical question for future research. Both fear and anxiety were elicited by the information focusing on the strained health care system. We do not 
know exactly what information in the text evoked fear and what evoked anxiety, or if some underlying variable, such as individual differences in proneness for fear or anxiety, or prior knowledge, played a role in the different emotional reactions. Nonetheless, given that the sample was fairly large and that all participants can be assumed to have had access to the same information, the fact that we find significant effects speak for the validity of the stimulus material and its capacity to evoke different emotions.

The differences in emotions between conditions were also fairly small, especially the difference in anger. Upon creating new stimulus material, it would be good to try to increase the differentiation in emotions evoked by the different conditions. Nevertheless, this study shows that even subtle changes in the focus on the Covid-19 reporting do influence what emotions citizens experience, which in turn may affect what policies they support.

Another limitation is that our study was only performed in one specific setting, the Swedish context, where the government handled the situation in a specific way that differ from the policy responses of many other countries' governments. Even though we believe that the mechanisms related to emotional response during a pandemic and how this affects political attitudes and behavior are of general nature, it would clearly be interesting to perform a similar experiment in another country context where the government responded to the crisis in a different way.

\section{Conclusions}

The present research has both theoretical and practical relevance. We contribute to the research on emotions and how they are related to political attitudes and behavior, particularly by splitting up fear and anxiety. Although elicited by the same stimulus, fear and anxiety have different effects on both policy preferences and political action intentions.

Practically, the results have importance for understanding how citizens respond to different reports of the pandemic, and how the responses may elicit support for different policies and political actions. Ultimately, this has consequences for health related behaviors. The fast-track emotions fear and anger seem both to increase support for restrictive policies which aim to reduce the spread of the virus and "flatten the curve". However, since these are high-arousal emotions, their effect is unlikely to be prolonged. Anxiety, in contrast, probably does have a prolonged effect, but this emotional response was unrelated to restrictive policies. 


\section{References}

American Psychiatric Association. (2013). Diagnostic and statistical manual of mental disorders: DSM-5 (5th ed). Washington, D.C.

Arndt, J., Greenberg, J., \& Cook, A. (2002). Mortality salience and the spreading activation of worldview-relevant constructs: exploring the cognitive architecture of terror management. Journal of Experimental Psychology: General, 131(3), 307.

Aroar, T. \& Grey, I. (2020). Health behaviour changes during COVID-19 and the potential consequences: A mini-review. Journal of Health Psychology, 25, 1155-1163.

Aquino, K., Tripp, T. M., \& Bies, R. J. (2001). How employees respond to personal offense: The effects of blame attribution, victim status, and offender status on revenge and reconciliation in the workplace. Journal of Applied Psychology, 86, 52-59.

Banks, A. J., \& Valentino, N. (2012). Emotional substrates of white racial attitudes. American Journal of Political Science, 56 (2), 286-297.

Bennett, M., \& Earwaker, D. (1994). Victims' responses to apologies: The effects of offender responsibility and offense severity. The Journal of Social Psychology, 134, 457-464.

Bodenhausen, G. V., Sheppard, L. A., \& Kramer, G. P. (1994). Negative affect and social judgment: The differential impact of anger and sadness. European Journal of Social Psychology, 24, 45-62.

Bol, D., Giani, M., Blais, A., Loewen, P. J. (2020). The effect of Covid-19 lockdowns on political support: Some good news for democracy? Quantitative Political Economy Research Group Working paper.

Brader, T., \& Marcus, G. E. (2013). Emotion and political psychology. In L. Huddy, D. O. Sears, \& J. S. Levy (Eds.), The Oxford handbook of political psychology (p. 165-204). Oxford University Press.

Bradfield, M., \& Aquino, K. (1999). The effects of blame attributions and offender likableness on forgiveness and revenge in the workplace. Journal of Management, 25, 607-631.

Burke, B. L., Martens, A., \& Faucher, E. H. (2010). Two Decades of Terror Management Theory: A Meta-Analysis of Mortality Salience Research. Personality and Social Psychology Review, 14(2), $155-195$.

Bäck, H., Fredén, A., Knapton, H., Renström, E. A., \& Sikström, S. (2020). Threat, emotions, and voting for the status quo in the Brexit referendum (unpublished manuscript).

Campbell, A. L. (2012). Policy Makes Mass Politics. Annual Review of Political Science 15(1): 333351. 
Carver, C. S., \& Harmon-Jones, E. (2009). Anger is an approach-related affect: Evidence and implications. Psychological Bulletin, 135, 183-204.

Cheng, C., Barceló, J., Hartnett, A. S., Kubinec, R., \& Messerschmidt, L. (2020). CoronaNet: A dyadic dataset of government responses to the Covid-19. arXiv Working Paper. Available at: https://osf.io/preprints/socarxiv/dkvxy/.

Darby, B. W., \& Schlenker, B. R. (1982). Children's reactions to apologies. Journal of Personality and Social Psychology, 43, 742-753.

Davis, M.D. and Stephan, W.G. (2011), Electromyographic Analyses of Responses to Intergroup Threat. Journal of Applied Social Psychology, 41: 196-218.

Denny, E. K. (2016). The Good Intention Gap: Poverty, Anxiety, and Implications for Political Action. https: //papers.ssrn.com/sol3/papers.cfm?abstract_id=2839926

Ekkekakis, P. (2013). The measurement of affect, mood, and emotion: A guide for health-behavioral research. Cambridge University Press.

Fetzer, T, Hensel, L., Hermle, J., \& Roth, C. (2020). Coronavirus Perceptions and Economic Anxiety. arXiv Working Paper. Available at: https://arxiv.org/abs/2003.03848.

Frijda, N. H. (1986). The emotions. Cambridge University Press.

Gadarian, S. H, Wallace Goodman, S., \& Pepinsky, T. B. (2020). Partisan Endorsement Experiments Do Not Affect Mass Opinion on COVID-19. SSRN Working Paper. Available at: https://ssrn.com/abstract $=3574605$.

Gibson, R., \& Cantijoch, M. (2013). Conceptualizing and measuring participation in the age of the internet: Is online political engagement really different to offline?. The Journal of Politics, 75, 701716.

Goodwin, J., Jasper, J. M., \& Polletta, F. (2001). Passionate politics: Emotions and social movements. Chicago: University of Chicago Press.

Gould, D. B. (2009). Moving politics: Emotion and ACT UP's fight against AIDS. Chicago: University of Chicago Press.

Gray, J. A., \& McNaughton, N. (2000). The neuropsychology of anxiety: An enquiry into the functions of the septo-hippocampal system (2nd ed.). New York: Oxford University Press.

Greenberg, J., Pyszczynski, T., Solomon, S., Rosenblatt, A., Veeder, M., Kirkland, S., \& Lyon, D. (1990). Evidence for terror management theory II: The effects of mortality salience on reactions to those who threaten or bolster the cultural worldview. Journal of Personality and Social Psychology, 58(2), 308-318. 
Harmon-Jones, E., Harmon-Jones, C., Abramson, L., \& Peterson, C. K. (2009). PANAS positive activation is associated with anger. Emotion, 9, 183-196.

Harmon-Jones, C., Bastian, B., \& Harmon-Jones, E. (2016). Detecting transient emotional responses with improved self-report measures and instructions. Emotion, 16, 1086-1096.

Harmon-Jones, E., Price, T. F., Gable, P. A., \& Peterson, C. K. (2014). Approach motivation and its relationship to positive and negative emotions. In M. M. Tugade, M. N. Shiota, \& L. D. Kirby (Eds.), Handbook of positive emotions (pp. 103-118). New York, NY: Guilford Press.

Harper, C. A., Satchell, L. P., Fido, D., \& Latzman, R. D. (2020). Functional fear predicts public health compliance in the COVID-19 pandemic. International journal of mental health and addiction.

Hayes, A. F. (2013). Introduction to mediation, moderation, and conditional process analysis: A regression-based approach. New York: The Guilford Press.

Helminen, V. K. (2018). Fear and anxiety as predictors of political attitudes: A prospective cohort study. Master thesis in Psychology, Helsinki University.

Holmes, E. A., O’Connor, R. C., Perry, V. H., et al. (2020). Multidisciplinary research priorities for the COVID-19 pandemic: A call for action for mental health science. The Lancet Psychiatry, 7, 547560.

Houghton, D. P. (2009). Political psychology: Situations, individuals, and cases. New York: Routledge.

Huang, Y. \& Zhao, N. (2020). Generalized anxiety disorder, depressive symptoms and sleep quality during COVID-19 outbreak in Chine: A web-based cross-sectional survey. Psychiatry Research, 288, 112954.

Jost, J. T., Glaser, J., Kruglanski, A. W., \& Sulloway, F. J. (2003). Political conservatism as motivated social cognition. Psychological Bulletin, 129 (3), 339-375.

Kenny, D. A. (2017). Mediation. Retrieved from www.DavidKenny.Net/Cm/mediate.html.

Klandermans, B., \& van Stekelenburg, J. (2013). Social movements and the dynamics of collective action. In L. Huddy, D. O. Sears, \& J. S. Levy (Eds.), The Oxford handbook of political psychology (p. 774-811). Oxford University Press.

Lambert, A. J., Eadeh, F. R., \& Hanson, E. J. (2019). Anger and its consequences for judgment and behavior: Recent developments in social and political psychology. Advances in Experimental Social Psychology, 59, 103-173.

Landau, M. J., Solomon, S., Greenberg, J., Cohen, F., Pyszczynski , T. , Arndt, J., et al., (2004). Deliver us from evil: The effects of mortality salience and reminders of 9/11 on support for President George W. Bush. Personality and Social Psychology Bulletin, 30 (9), 1136-1150. 
Lang, P. J., Davis, M., \& Öhman, A. (2000). Fear and anxiety: Animal models and human cognitive psychophysiology. Journal of Affective Disorders, 61(3), 137-159.

Lerner, J. S., Gonzalez, R. M., Small, D. A., \& Fischhoff, B. (2003). Effects of fear and anger on perceived risks of terrorism: A national field experiment. Psychological Science, 14, 144-150.

Lerner, J. S., \& Keltner, D. (2001). Fear, anger, and risk. Journal of Personality and Social Psychology, 81 (1), 146-159.

Li, W., Yang, Y., Liu, Z. H. et al. (2020). Progression of mental health services during the COVID-19 outbreak in China. International Journal of Biological Sciences, 16, 1732-1738.

Lickel, B., Miller, N., Stenstrom, D. M., Denson, T. F., \& Schmader, T. (2006). Vicarious retribution: The role of collective blame in intergroup aggression. Personality and Social Psychology Review, 10, 372-390.

Marcus, G. E., Neuman, W. R., \& MacKuen, M. B. (2000). Affective intelligence and political judgment. Chicago: University of Chicago Press.

McKeever, A. (2020). Immigration policy and right-wing populism in Western Europe. Springer Nature.

Merolla, J. L., \& Zechmeister, E. J. (2009). Democracy at risk: How terrorist threats affect the public. Chicago: University of Chicago Press.

Nail, P. R., \& McGregor, I. (2009). Conservative shift among liberals and conservatives following 9/11/01. Social Justice Research, 22, 231-240.

Oser, J., Hooghe, M., \& Marien, S. (2013). Is online participation distinct from offline participation? A latent class analysis of participation types and their stratification. Political Research Quartlery, 66, 91-101.

Perkins, A. M., Inchley-Mort, S. L., Pickering, A. D., Corr, P. J., \& Burgess, A. P. (2012). A facial expression for anxiety. Journal of Personality and Social Psychology, 102 (5), 910-924.

Poteat, V. P., \& Mereish, E. H. (2012), Ideology, Prejudice, and Attitudes Toward Sexual Minority Social Policies and Organizations. Political Psychology, 33: 211-224.

Pyszczynski, T., Solomon, S., \& Greenberg, J. (2003). In the wake of 9/11: Rising above the terror. In T. Pyszczynski, S. Solomon, \& J. Greenberg, In The Wake of 9/11: The Psychology Of Terror (pp. 189-198). Washington, DC, US: American Psychological Association.

Sadler, M. S., Lineberger, M., Correll, J., \& Park, B. (2005). Emotions, attributions, and policy endorsement in response to the September 11th terrorist attacks. Basic and Applied Social Psychology, 27, 249-258. 
Skitka, L. J., Bauman, C. W., Aramovich, N. P., \& Morgan, G. S. (2006). Confrontational and preventative policy responses to terrorism: Anger wants a fight and fear wants "them" to go away. Basic and Applied Social Psychology, 28, 375-384.

Slovic, P. (1987). Perception of risk. Science, 236(4799), 280-285.

Soomro, G. M. (2012). Obsessive compulsive disorder. BMJ Clinical Evidence.

SVT - Swedish Television (2020). Se hur resandet minskade över påskhelgen [See how the travelling was reduced during Easter weekend]. https://www.svt.se/nyheter/se-hur-resandet-minskade-underpaskhelgen

Sylvers, P., Lilienfeld, S. O., \& LaPrairie, J. L. (2011). Differences between trait fear and trait anxiety: Implications for psychopathology. Clinical Psychology Review, 31(1), 122-137.

Valentino, N., Brader, T., Groenendyk, E., Gregorowicz, K., \& Hutchings, V. (2011). Election Night's Alright for Fighting: The Role of Emotions in Political Participation. The Journal of Politics, 73(1), 156-170.

Watson, D., Clark, L. A., \& Tellegen, A. (1988). Development and validation of brief measures of positive and negative affect: the PANAS scales. Journal of Personality and Social Psychology, 54, 1063-1070.

World Health Organization. (1992). The ICD-10 classification of mental and behavioural disorders: Clinical descriptions and diagnostic guidelines. Geneva: World Health Organization

Öhman, A., \& Mineka, S. (2001). Fears, phobias, and preparedness: Towards an evolved module of fear and fear learning. Psychological Review, 108 (3), 483-522.

\section{Conflict of Interest}

The authors declare that the research was conducted in the absence of any commercial or financial relationships that could be construed as a potential conflict of interest. 


\section{Tables}

Table 1. Means and standard deviations for the emotion indices split on condition.

\begin{tabular}{lllll}
\hline \multicolumn{5}{c}{ Condition } \\
\hline Outcome & Fear/Anxiety & Anger & $\mathrm{p}$ & Cohens' D \\
\hline Fear & $3.23(1.50)$ & $2.86(1.40)$ & $<.001$ & 0.26 \\
Anger & $2.78(1.46)$ & $3.00(1.48)$ & .016 & 0.15 \\
Anxiety & $3.72(1.44)$ & $3.39(1.37)$ & $<.001$ & 0.24 \\
Sadness & $3.47(1.47)$ & $3.49(1.40)$ & .03 & 0.01 \\
Disgust & $2.07(1.23)$ & $2.07(1.25)$ & .99 & \\
Empathy & $5.22(1.30)$ & $5.16(1.34)$ & .52 & \\
\hline
\end{tabular}

Table 2. Means and standard deviations for the outcome variables split on condition.

\begin{tabular}{llll}
\hline \multicolumn{4}{l}{ Condition } \\
& Fear/anxiety & Anger & Total \\
\hline Economy policy support & $5.41(1.01)$ & $5.49(1.05)$ & $5.43(1.03)$ \\
Restrictive policy support & $3.60(1.33)$ & $3.57(1.29)$ & $3.59(1.31)$ \\
Political actions & $3.44(1.49)$ & $3.58(1.44)$ & $3.51(1.47)$ \\
& & & \\
\hline
\end{tabular}

Table 3. Bivariate correlations between the emotion indices and the outcome variables.

\begin{tabular}{lllllll}
\hline & Fear & Anger & Anxiety & Sadness & Disgust & Empathy \\
\hline Economy & $.14^{* * *}$ & $.09^{* *}$ & $.17^{* * *}$ & $.14^{* * *}$ & .04 & $.26^{* * *}$ \\
Restrictive & $.35^{* * *}$ & $.26^{* * *}$ & $.29^{* * *}$ & $.22^{* * *}$ & $.25^{* * *}$ & $.07^{*}$ \\
Political & $.18^{* * *}$ & $.26^{* * *}$ & $.24 * * *$ & $.18^{* * *}$ & $.14^{* * *}$ & $.20^{* * *}$ \\
actions & & & & & & \\
\hline
\end{tabular}

Note: $* * * p<.001, * * p<.01, * p<.05$ 
Table 4. Parallel mediation models for policy support and political action intentions, with emotions as mediators and condition as independent variable.

\begin{tabular}{|c|c|c|c|c|c|c|c|}
\hline & $\begin{array}{l}\text { Anger } \\
\text { (M1) }\end{array}$ & $\begin{array}{l}\text { Fear } \\
\text { (M2) }\end{array}$ & $\begin{array}{l}\text { Anxiety } \\
\text { (M3) }\end{array}$ & $\begin{array}{l}\text { Sadness } \\
\text { (M4) }\end{array}$ & $\begin{array}{l}\text { Restrictive } \\
\text { policy } \\
\text { support (Y) }\end{array}$ & $\begin{array}{l}\text { Economy } \\
\text { policy } \\
\text { support } \\
\text { (Y) }\end{array}$ & $\begin{array}{l}\text { Political } \\
\text { action } \\
\text { intentions } \\
\text { (Y) }\end{array}$ \\
\hline Antecedent & Coeff & Coeff & Coeff & Coeff. & Coeff. & Coeff & Coeff. \\
\hline Constant & $\begin{array}{l}2.66 \\
(0.29) * * *\end{array}$ & $\begin{array}{l}2.84 \\
(0.29) * * *\end{array}$ & $\begin{array}{l}3.46 \\
(0.28) * * *\end{array}$ & $\begin{array}{l}3.29 \\
(0.30) * * *\end{array}$ & $\begin{array}{l}2.96 \\
(0.27)^{* * *}\end{array}$ & $\begin{array}{l}5.25 \\
(0.23) * * *\end{array}$ & $\begin{array}{l}2.25 \\
(0.30) * * *\end{array}$ \\
\hline Condition & $\begin{array}{l}0.16 \\
(0.05) * * *\end{array}$ & $\begin{array}{l}-0.15 \\
(0.05)^{* * *}\end{array}$ & $\begin{array}{l}-0.13 \\
(0.05)^{* *}\end{array}$ & $\begin{array}{l}-0.09 \\
(0.05)\end{array}$ & $0.03(0.04)$ & $0.05(0.03)$ & $\begin{array}{l}0.08 \\
(0.04)\end{array}$ \\
\hline Anger (M1) & - & - & - & - & $0.08(0.03)^{*}$ & $0.00(0.03)$ & $\begin{array}{l}0.13 \\
(0.04) * * *\end{array}$ \\
\hline Fear (M2) & - & - & - & - & $\begin{array}{l}0.27 \\
(0.05)^{* * *}\end{array}$ & $\begin{array}{l}-0.03 \\
(0.04)\end{array}$ & $\begin{array}{l}-0.07 \\
(0.06)\end{array}$ \\
\hline $\begin{array}{l}\text { Anxiety } \\
\text { (M3) }\end{array}$ & - & - & - & - & $-0.03(0.06)$ & $\begin{array}{l}0.13 \\
(0.05)^{* *}\end{array}$ & $\begin{array}{l}0.24 \\
(0.07) * * *\end{array}$ \\
\hline $\begin{array}{l}\text { Sadness } \\
\text { (M4) }\end{array}$ & - & - & - & - & $0.01(0.04)$ & $0.02(0.03)$ & $\begin{array}{l}-0.00 \\
(0.05)\end{array}$ \\
\hline Gender (C1) & $\begin{array}{l}0.40 \\
(0.10) * * *\end{array}$ & $\begin{array}{l}0.59 \\
(0.10) * * *\end{array}$ & $\begin{array}{l}0.61 \\
(0.09)^{* * *}\end{array}$ & $\begin{array}{l}0.48 \\
(0.10)^{* * *}\end{array}$ & $-0.01(0.08)$ & $0.13(0.07)$ & $\begin{array}{l}0.10 \\
(0.09)\end{array}$ \\
\hline Age (C2) & $\begin{array}{l}-0.01 \\
(0.00) * * *\end{array}$ & $\begin{array}{l}-0.00 \\
(0.00)\end{array}$ & $\begin{array}{l}-0.00 \\
(0.00)^{*}\end{array}$ & $\begin{array}{l}0.00 \\
(0.00)\end{array}$ & $-0.00(0.00)$ & $0.00(0.00)$ & $\begin{array}{l}-0.01 \\
(0.00) * * *\end{array}$ \\
\hline $\begin{array}{l}\text { Education } \\
\text { (C3) }\end{array}$ & $\begin{array}{l}-0.09 \\
(0.05)^{*}\end{array}$ & $\begin{array}{l}-0.05 \\
(0.05)\end{array}$ & $\begin{array}{l}-0.04 \\
(0.04)\end{array}$ & $\begin{array}{l}-0.03 \\
(0.04)\end{array}$ & $\begin{array}{l}-0.13 \\
(0.04)^{* * *}\end{array}$ & $\begin{array}{l}-0.11 \\
(0.03) * * *\end{array}$ & $\begin{array}{l}0.05 \\
(0.04)\end{array}$ \\
\hline $\begin{array}{l}\text { Left-right } \\
\text { (C4) }\end{array}$ & $\begin{array}{l}0.02 \\
(0.02)\end{array}$ & $\begin{array}{l}-0.03 \\
(0.02)\end{array}$ & $\begin{array}{l}-0.04 \\
(0.02)\end{array}$ & $\begin{array}{l}-0.02 \\
(0.02)\end{array}$ & $-0.02(0.02)$ & $0.01(0.02)$ & $\begin{array}{l}-0.02 \\
(0.02)\end{array}$ \\
\hline $\begin{array}{l}\text { Liberal- } \\
\text { Conservative } \\
\text { (C5) }\end{array}$ & $\begin{array}{l}0.11 \\
(0.03) * * *\end{array}$ & $\begin{array}{l}0.10 \\
(0.03) * * *\end{array}$ & $\begin{array}{l}0.07 \\
(0.03)^{* *}\end{array}$ & $\begin{array}{l}0.05 \\
(0.03)\end{array}$ & $\begin{array}{l}0.11 \\
(0.02) * * *\end{array}$ & $\begin{array}{l}-0.02 \\
(0.02)\end{array}$ & $\begin{array}{l}-0.07 \\
(0.02)^{*}\end{array}$ \\
\hline $\begin{array}{l}\text { Political } \\
\text { interest (C6) }\end{array}$ & $\begin{array}{l}0.03 \\
(0.02)\end{array}$ & $\begin{array}{l}0.03 \\
(0.02)\end{array}$ & $\begin{array}{l}0.04 \\
(0.02)^{*}\end{array}$ & $\begin{array}{l}0.03 \\
(0.02)\end{array}$ & $\begin{array}{l}-0.05 \\
(0.02)^{*}\end{array}$ & $\begin{array}{l}-0.02 \\
(0.01)\end{array}$ & $\begin{array}{l}0.16 \\
(0.02)^{* * *}\end{array}$ \\
\hline & $\mathrm{R} 2=0.08$ & $\mathrm{R} 2=0.07$ & $\mathrm{R} 2=0.07$ & $\mathrm{R} 2=0.04$ & $\mathrm{R} 2=0.18$ & $\mathrm{R} 2=0.06$ & $\mathrm{R} 2=0.18$ \\
\hline & $\mathrm{F}(7,943)$ & $\mathrm{F}(7,943)$ & F $(7,943)$ & F $(7,943)$ & $\mathrm{F}(11,939)=$ & $\begin{array}{l}\mathrm{F}(11,939) \\
-57 * * *\end{array}$ & $\mathrm{~F}(11,939)$ \\
\hline & $11.21 * * *$ & $9.45 * * *$ & $9.41 * * *$ & $4.90 * * *$ & & & $18.73 * * *$ \\
\hline
\end{tabular}

Note: $* * * \mathrm{p}<.001, * * \mathrm{p}<.01, * \mathrm{p}<.05$

Condition is dummy coded with fear/anxiety $=0$, anger $=1$.

Gender is dummy coded with men $=0$, women $=1$. 
Table 5. Direct and indirect effects of condition on policy support and political action intentions from bootstrapping with confidence intervals in parenthesis.

\begin{tabular}{lllll}
\hline & $\begin{array}{l}\text { Restrictive policy } \\
\text { support }\end{array}$ & $\begin{array}{l}\text { Economy policy } \\
\text { support }\end{array}$ & $\begin{array}{l}\text { Political } \\
\text { intentions }\end{array}$ \\
\hline $\begin{array}{l}\text { Direct effects } \\
\text { Indirect effects }\end{array}$ & $0.02(-0.05 ; 0.10)$ & $0.05(-0.02 ; 0.11)$ & $0.11(-0.06 ; 0.29)$ \\
Fear & $-0.04(-0.07 ;-0.01)$ & $0.00(-0.04 ; 0.00)$ & $0.03(-0.01 ; 0.08)$ \\
Anger & $0.01(0.001 ; 0.03)$ & $-0.00(-0.01 ; 0.01)$ & $0.04(0.01 ; 0.08)$ \\
Anxiety & $0.00(-0.02 ; 0.02)$ & $-0.03(-0.07 ;-0.002)$ & $-0.05(-0.12 ;-0.01)$ \\
Sadness & $0.00(-0.01 ; 0.01)$ & $0.01(-0.01 ; 0.02)$ & $-0.00(-0.03 ; 0.02)$
\end{tabular}

Note: Level of confidence for all confidence intervals is 95\%. Results are based on 5000 bootstrap samples.

Figure 1. The effect of condition on support for Economic and Restrictive policies (panel A and B), and Political Action intentions (Panel C), via fear, anxiety and anger.
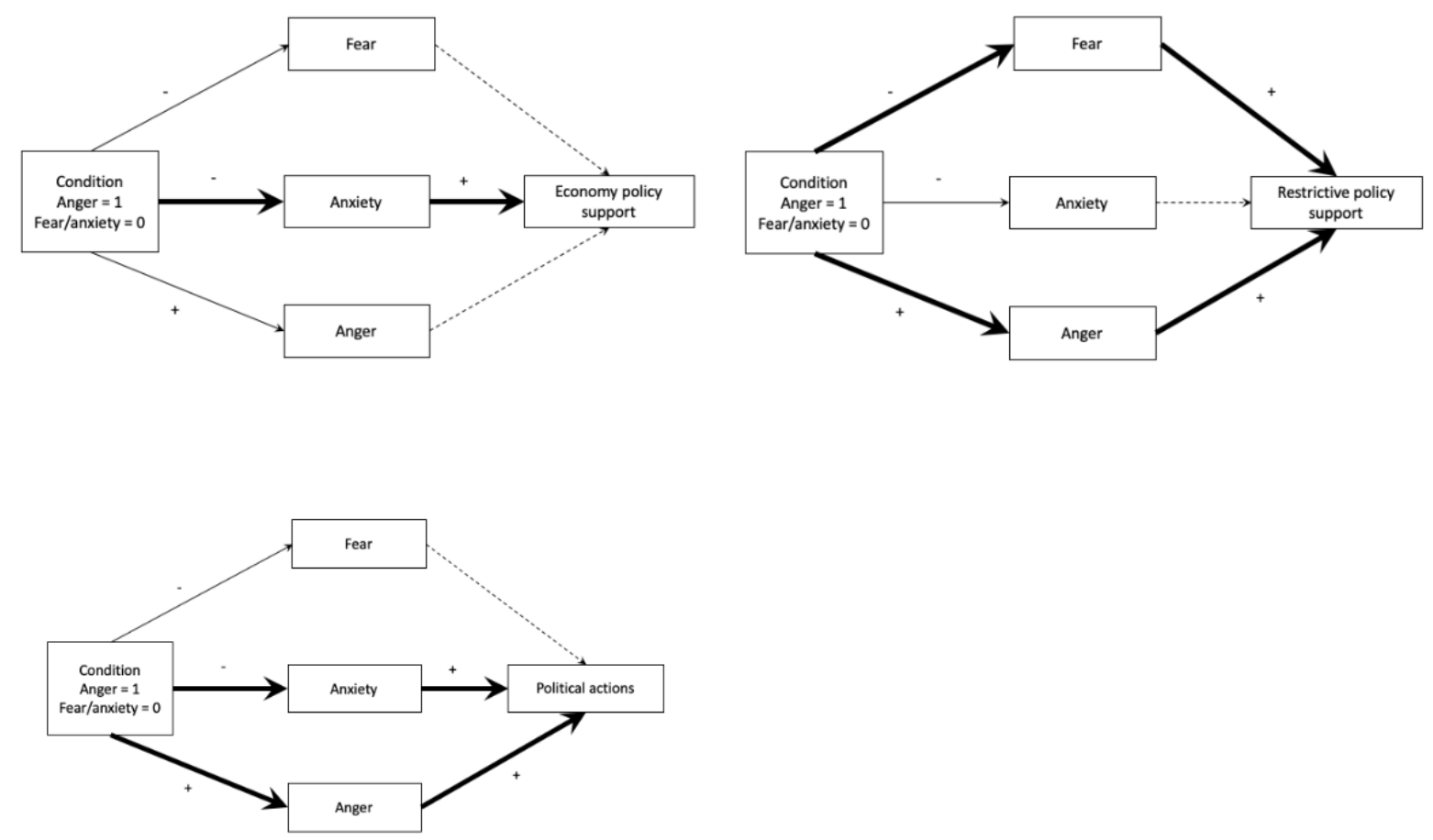